\title{
The Seawater Sr/Ca ratio in the past 50 Myr from Bulk Carbonate Sediments Corrected for Diagenesis
}

\author{
SHUO ZHANG ${ }^{1 *}$, RENJIE ZHOU ${ }^{2}$, AND DONALD J. \\ DEPAOLO $^{3}$ \\ ${ }^{1}$ State Key Laboratory of Hydroscience and Engineering, \\ Department of Hydraulic Engineering, Tsinghua \\ University, Beijing, 100084, China (*correspondence: \\ zhangs2019@tsinghua.edu.cn) \\ ${ }^{2}$ Department of Geography and Geology, Sam Houston State \\ University, 1905 University Avenue, Huntsville, TX \\ 77340, USA (rxz013@shsu.edu) \\ ${ }^{3}$ Energy Geosciences Division, Lawrence Berkeley National \\ Laboratory, 1 Cyclotron Rd, Berkeley, CA 94720, USA \\ (djdepaolo@lbl.gov)
}

The strontium/calcium $(\mathrm{Sr} / \mathrm{Ca})$ ratio in paleoseawater is important for evaluating the global fluxes of continental weathering products and carbonate deposition in the oceans. Existing reconstructions of the paleoseawater $\mathrm{Sr} / \mathrm{Ca}$ ratio using different methods give conflicting results. We use a modeling approach to estimate paleo-Sr/Ca for the past 50 million years that uses pore fluid chemistry and bulk sediment measurements of carbonate ooze and chalk from the Ontong Java Plateau as input. The effects of diagenesis in modifying the $\mathrm{Sr} / \mathrm{Ca}$ ratio recorded in bulk carbonate sediments are estimated using a reactive transport model, and those effects are accounted for in determining the initial $\mathrm{Sr} / \mathrm{Ca}$ ratio of the biogenic carbonate sediments. The $\mathrm{Sr} / \mathrm{Ca}$ of the paleo-oceans is calculated based on an effective partition coefficient (0.198) inferred from $\mathrm{Sr} / \mathrm{Ca}$ in modern sediments. The model simulates deposition of sediments on the seafloor, reactions between pore fluid and solid (dissolution and precipitation of calcite), and diffusion within the pore fluid. Measured pore fluid $\mathrm{Sr}, \mathrm{Ca}$ and sulfate concentrations provide input for the $\mathrm{Sr}$ model. This approach, applied to four Ocean Drilling Program (ODP) sites $(803,805,806,807)$ that have long Cenozoic records of carbonate deposition, indicates that the $\mathrm{Sr} / \mathrm{Ca}$ ratio of seawater has increased slowly over the past 50 million years from a value of about $8 \mathrm{mmol} / \mathrm{mol}$ to the modern value of 9.4 , with fluctuations of about \pm 1 over 10 Myr periods. This result is consistent with previous estimates based on foraminifera and coral aragonite, but differs from recent estimates obtained with other approaches. The nearconstant seawater $\mathrm{Sr} / \mathrm{Ca}$ over the past 50 million years is consistent with likely weathering sources to the oceans. The fluctuations suggest that there were modest shifts in the aragonite/calcite ratio of marine carbonate. 